\title{
Clinical placement models for undergraduate health professions students: a scoping review
}

\author{
Champion N. Nyoni", Lizemari Hugo-Van Dyk and Yvonne Botma
}

\begin{abstract}
Background: Clinical learning is fundamental to undergraduate health professions students. There are several calls for the transformation of health professions education, which have direct implications on clinical learning. Clinical placement models provide structure to clinical learning. Therefore, this scoping review could contribute to supporting curriculum transformation to enhance learning in the clinical environments for undergraduate health professions students.
\end{abstract}

Objectives: This scoping review identified the characteristics of research evidence related to mapping the purpose, methodologies used, outcomes, and specific recommendations associated with clinical placement models in undergraduate health professions education.

Design: A scoping review method was used in this study. A search string developed from the title of the review was used to search online databases to identify research published between January 2000 and March 2020.

Results: Forty-eight articles reporting on ten clinical placement models were included in this review. The majority of these articles originated from Australia and predominantly report on nursing. The aims of these articles aligned with the evaluation of the implementation of a clinical placement model. Seven categories of outcomes of the clinical placement models are reported namely, relationships, influence, environment, facilitation, inputs, knowledge scores, and student perceptions.

Conclusions: As clinical learning is fundamental to undergraduate health professions education, clinical placement models should prioritise the development of competence among undergraduate students. Insights into outcomes reported in literature could guide educators in fostering optimal learning in students who may then be able to influence community health outcomes positively.

Keywords: Clinical placement, Models, Health professions education, Undergraduate, Scoping review

\section{Background}

The last decade saw various calls for innovation in undergraduate health professions education. Frenk et al. [1], in their seminal article, support the adoption of transformative education, while the World Health

*Correspondence: nyonic@ufs.ac.za

School of Nursing, Faculty of Health Sciences, University of the Free State, Bloemfontein, South Africa
Organization (WHO), in the Framework for Action on Interprofessional Education and Collaborative Practice [2], argues for the infusion of interprofessional education in undergraduate health professions programmes. The Carnegie Foundation for the Advancement of Teaching highlights the need for reforms in health professions educations, which foster the development of learning environments that integrate classroom and clinical concepts emphasising clinical reasoning [3]. 
More recently, the State of the World Nursing report has reaffirmed the need for competency-based education (WHO, [4]). These recommendations to undergraduate health professions education are made against a backdrop of increased student numbers, resource limitations, healthcare system challenges and emerging health crises, such as the COVID-19 pandemic, inevitably implying that traditional clinical placement models may not support learning [5].

Clinical placement models are a theoretical structure that guides educators and health professional students in their engagement with authentic clinical opportunities [5]. This theoretical structure integrates the purpose of the placement, the placement activity, the location of the placement - including the length of placement, students, supervision and placement facilitators [6]. Clinical placements are critical in health professions for the application of learnt clinical skills in authentic settings. Clinical placement models that increase placement capacity are cost-effective and ensure a positive learning culture, are critical for competence development [7]. Innovations in undergraduate health professions education programmes must integrate relevant clinical placement models into their mainstream education programmes.

The calls for a transformation in health professions education merge with theoretical shifts that foster the adoption of active education models as an alternative to passive teacher-centred models [8]. Active education models are oriented towards learning, shifting the education responsibility to the student, who is expected to place himself or herself at the centre of the education process [9]. Constructivism, as an educational theory, advances active learning, and has been reported in underpinning the design and development of undergraduate health professions education programmes in some countries [10]. In such programmes, the students create meaning by connecting their ideas with their experiences, both inside the classroom and out. Clinical placement models should enable undergraduate health professions students to transfer their learning into practice and be aligned with active learning models.

At the time of this study, the authors could not find a comprehensive review of post-2000 literature on clinical placement models in undergraduate health professions education. The aim of this article is to report on a scoping review that sought to answer the question "What is known from the literature regarding clinical placement models for undergraduate health professions students?" A mapping of the literature on clinical placement models used in undergraduate health professions education could contribute to supporting programme directors, clinical educators and curriculum planners in fostering optimal learning for students in the clinical environment.

\section{Methods}

\section{Scoping review method}

The scoping review method as described by Peters et al. 2020 (cited in Aromatis \& Munn, 2020) [11] was used. Scoping reviews are an approach to synthesising knowledge that addresses an exploratory research question aimed at mapping key concepts, evidence characteristics, recommendations and gaps in a specific research area [11, 12]. Aromatis and Munn [11] and the Preferred Report Items for Systematic and Meta-analysis extension for Scoping review (PRISMA-ScR) as described by Tricco et al. [13] influenced the conceptualisation, execution and reporting of this scoping review. This scoping review was executed through several steps namely the search strategy which included the search string, the information sources and the inclusion criteria. Additional steps were; a search for the evidence, selection of evidence, analysis of the evidence, and presentation of the results. The Preferred Reporting Items for Systematic Reviews and MetaAnalysis Protocols (PRISMA-P) guided the development of a priori protocol [14]. The Health Sciences Ethics Committee (HSREC) of the University of the Free State (UFS) approved the protocol (HSD 2020/0572/2605), registered at the Open Science Framework (See https:// osf.io/8e463).

\section{The search string}

The Medical Subject Headings (MeSH) keywords influenced the generation of the search string based on the key concepts of the title. Through discussion between the authors and a university librarian, and secondary to several trials searches, the final search string is presented in Fig. 1.

\section{Information sources}

The following electronic bibliographic databases were searched, namely CINAHL with Full Text, MEDLINE with Full Text, Academic Search Ultimate, APA PsycInfo, Health Source, Nursing/Academic Edition, ERIC, Africa-Wide Information, Open Dissertations, and APA PsycArticles. Additional sources of information through an ancestry search after examining the reference lists of articles included in the final search supplemented the literature.

\section{Inclusion criteria}

This review sought to include literature regarding clinical placement models used in undergraduate health professions education. Peer-reviewed research articles were included if they were published between January 2000 and April 2020 and available in English. Studies applying different research designs inclusive of qualitative, quantitative and mixed methods research were included in 
((educat* or training $\left.{ }^{*}\right)$ n2 ("Health profession *" OR nurs * OR medical OR physiotherap* or "occupational therap*" OR optometr* or surg* OR pharmac* OR health OR Dentist* OR paramedic* OR dietician* or Biokinetic*))

\begin{abstract}
AND
(model* n2 ("clinical placement" OR "clinical learning" OR "clinical education" OR "clinical practice" OR placement $\left.{ }^{*}\right)$ )
\end{abstract}

Fig. 1 Search string

this review. However, grey literature, reviews and studies referring to clinical teaching or facilitation, which only referred to an aspect of clinical placement model, were excluded.

\section{Selection of source of evidence}

The initial search produced 879 hits and after automatic de-duplication resulted in 438 hits for the first round of screening. The authors independently screened and selected the evidence, meetings were held to discuss the findings of the individual screening. Discrepancies among the authors were resolved through discussion. An initial examination of titles and abstracts against the inclusion criteria eliminated 371 records that did not meet the inclusion criteria. Through a university librarian, full-text articles were sought and screened against the same inclusion criteria. Fifteen full-text articles did not meet the inclusion criteria and were eliminated. A further four full-text articles were eliminated as they were not in English, and translation efforts were futile (see Fig. 2).

\section{Charting the data}

The authors jointly developed a data charting form. The data charting form was independently piloted on two included articles by the authors, and discussions enhanced its refinement. Characteristics of the articles, the professions, the research design, and the purpose of the research, data collection methods, specific outcomes, and recommendations from the included studies were charted. One author charted this data on an electronic tool supported by the ATLAS.ti platform, and the other two authors independently verified the accuracy of the data. Discussions resolved inconsistencies and amended some missing data (see Table 1).

\section{Analysis of data}

Multiple steps were applied in analysing the charted data. In the initial step, the authors examined the characteristics of the included articles, namely the year of publication, the country where the research was conducted, the profession and the research design. Frequencies in each of these characteristics were tallied. The subsequent step examined the outcomes and recommendations of the research studies included in this review. In this step, the authors inductively thematised the outcomes of the studies to generate 19 broad themes influenced by the review question. The included articles were then clustered based on the reported clinical placement model and appraised against the 19 broad themes. Furthermore, the themes were combined into seven descriptive categories.

\section{Results}

The results of this review are presented through a discussion of the characteristics of the included studies and the outcomes of the models.

\section{Characteristics of the included studies}

Forty-eight full-text articles were included in this scoping review. The included articles comprised a range of studies from a 20year period and were from Australia $(n=22)$, the United States $(n=13)$, the United Kingdom $(n=8)$ and the Republic of Ireland $(n=5)$. Seven professional disciplines were represented, namely Nursing $(n=25)$, Medicine $(n=7)$, Occupational Therapy $(n=6)$, Physiotherapy $(\mathrm{n}=5)$, Midwifery $(n=3)$, Dietetics $(n=1)$ and Speech and Language Therapy $(\mathrm{n}=1)$. Qualitative research $(n=19)$ was the predominant design used in most of the included studies followed by quantitative designs $(n=13)$, then mixed methods $(n=6)$, multiple methods $(n=4)$, non-specified designs $(n=4)$, and case study research $(n=2)$. Ten clinical 
Records identified data bases $(\mathrm{n}=\mathbf{8 7 9})$

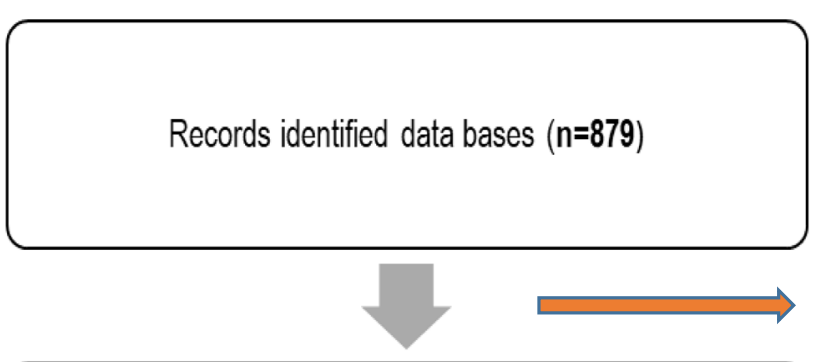

Automatic deduplication

Duplicates removed $(n=411)$

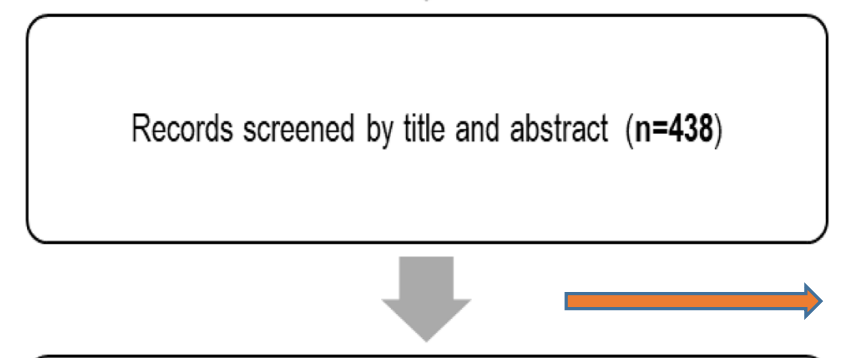

Records not meeting inclusion criteria $(n=371)$

Articles considered for full text screening $(n=67)$

Full text articles included for review $(n=52)$

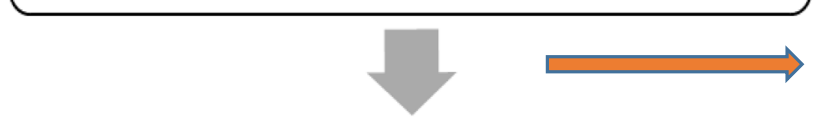

Full text articles not meeting the inclusion criteria $(n=15)$

Collaborative models $(n=17)$, combination models $(n=6)$, innovative models $(n=6)$, dedicated education units model $(n=5)$, longitudinal integrated clerkships ( $n=5)$, block placement model (n 3), studentled models $(n=2)$, spoke and hub model $(n=2)$, practice- or projectbased model $(n=1)$, role-emerging model $(n=1)$
Full text excluded due to language limitations $(n=4)$

Final list of included articles $(n=48)$

Fig. 2 Data selection process 


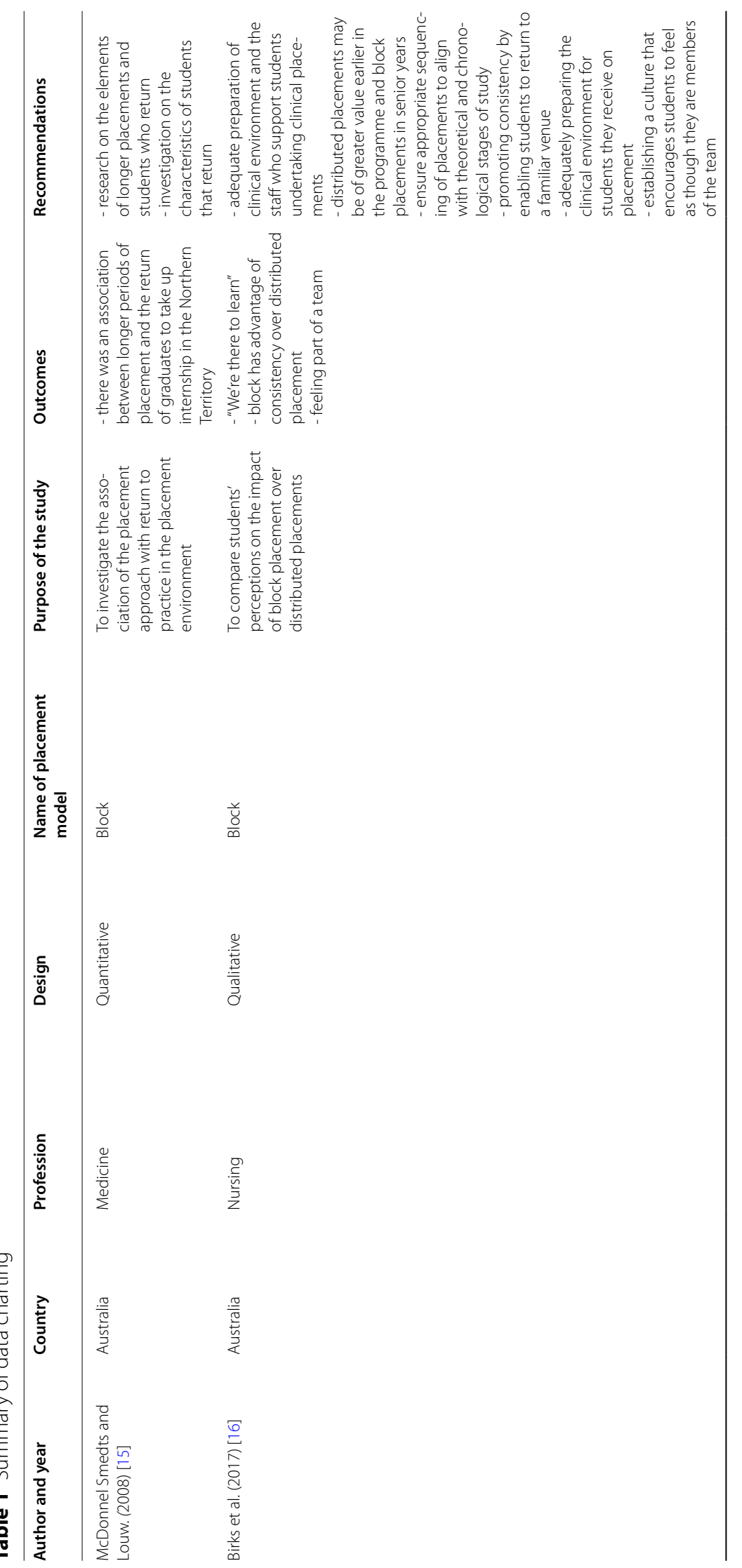




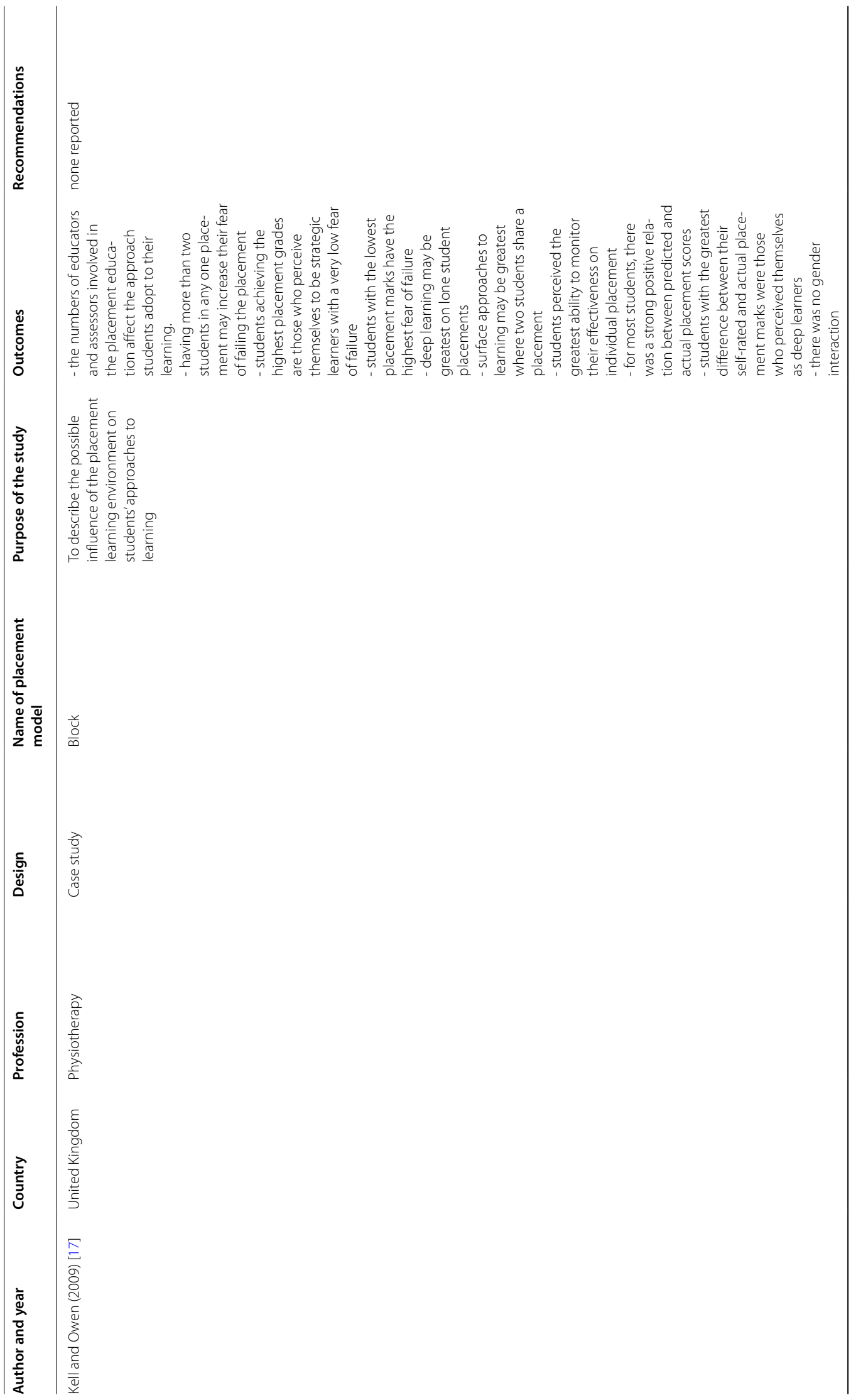




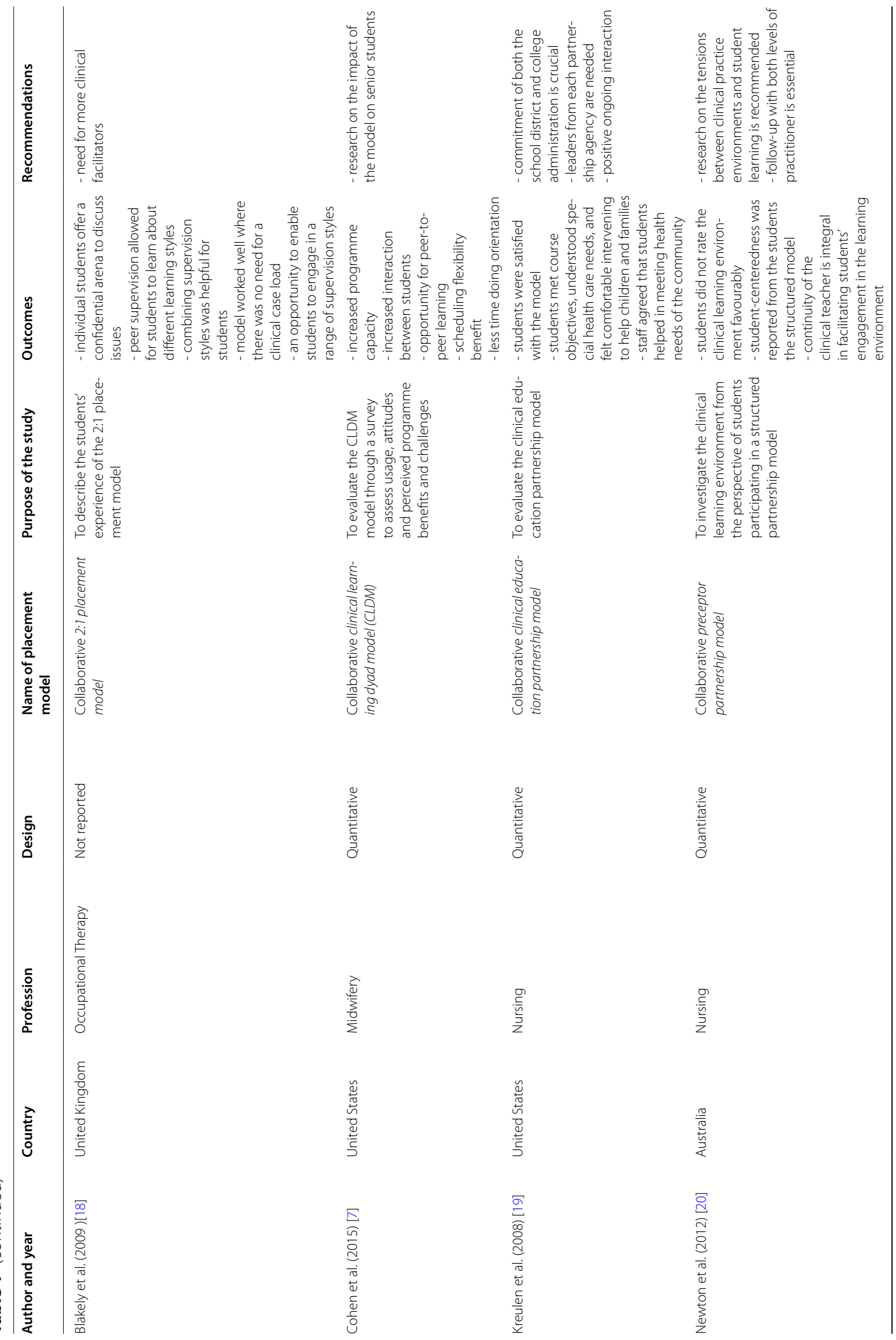




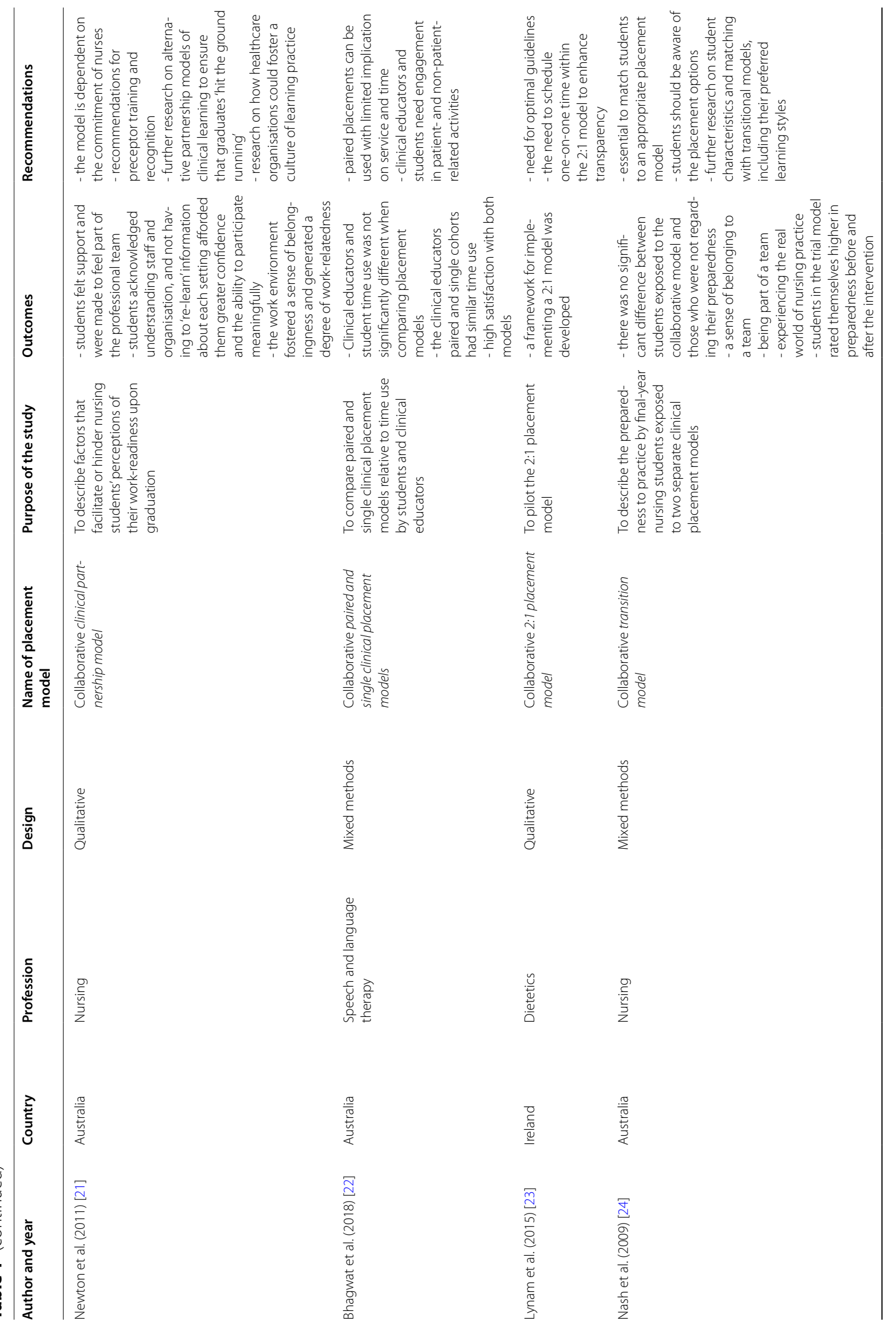


Nyoni et al. BMC Medical Education $\quad$ (2021) 21:598

Page 9 of 26

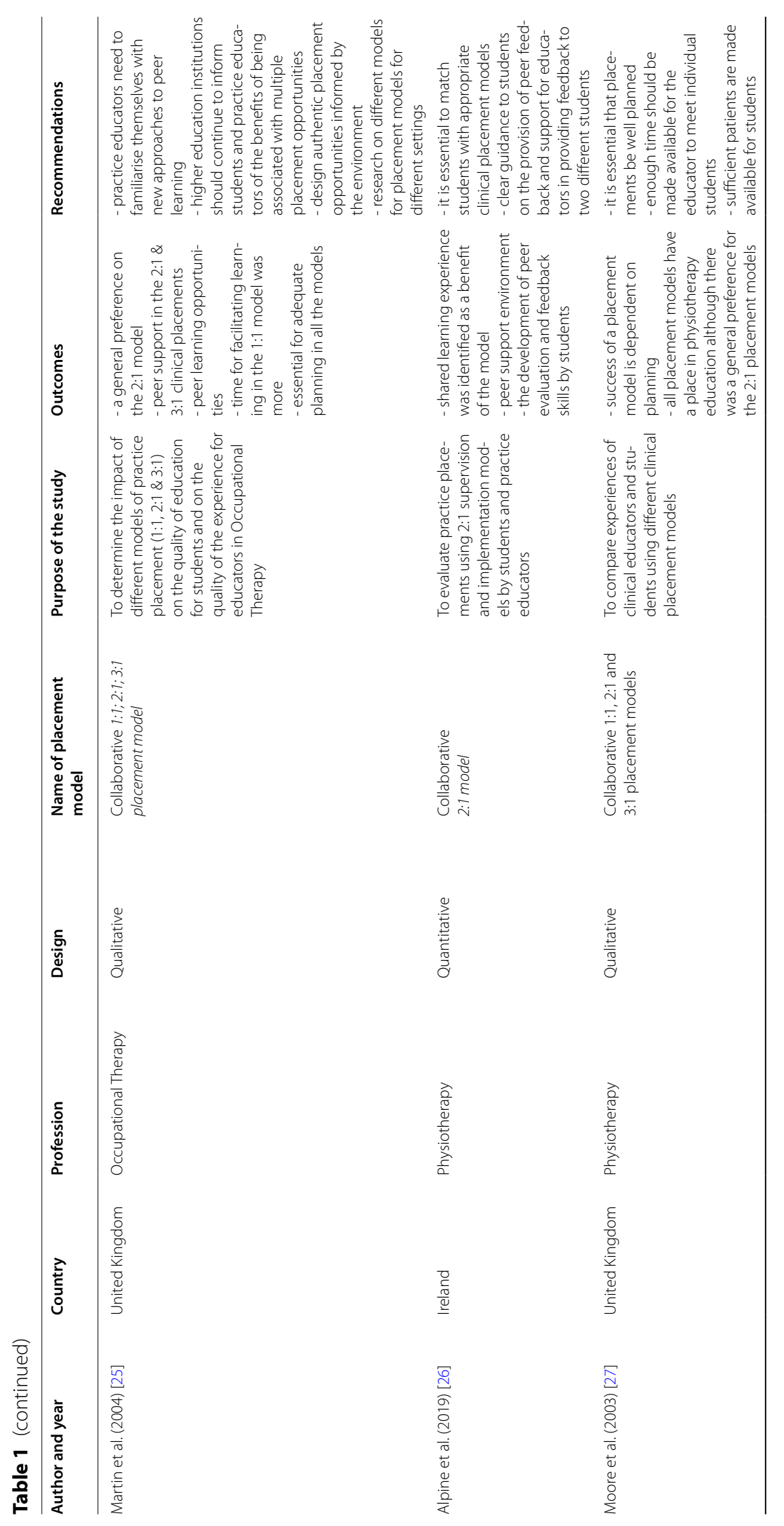




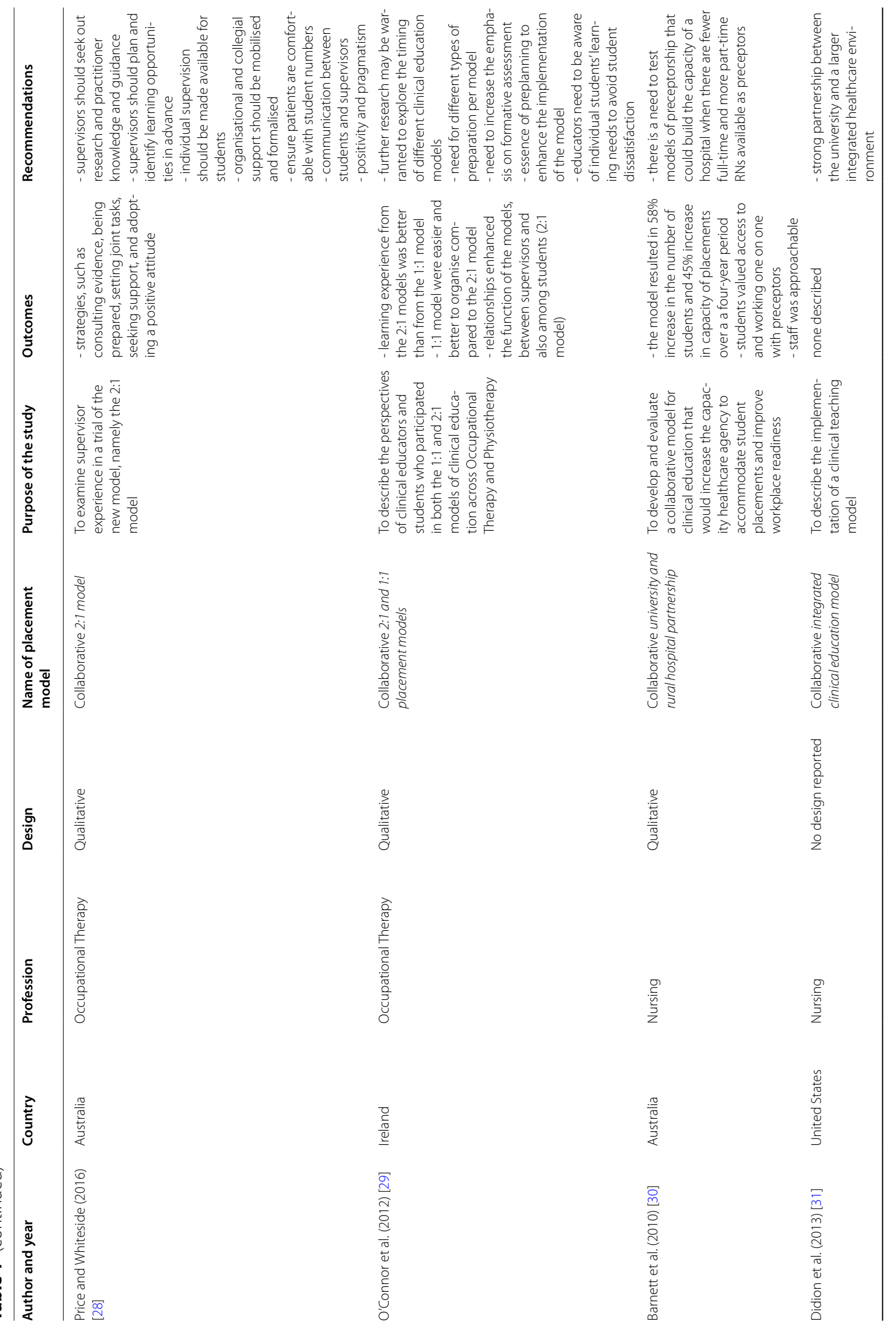




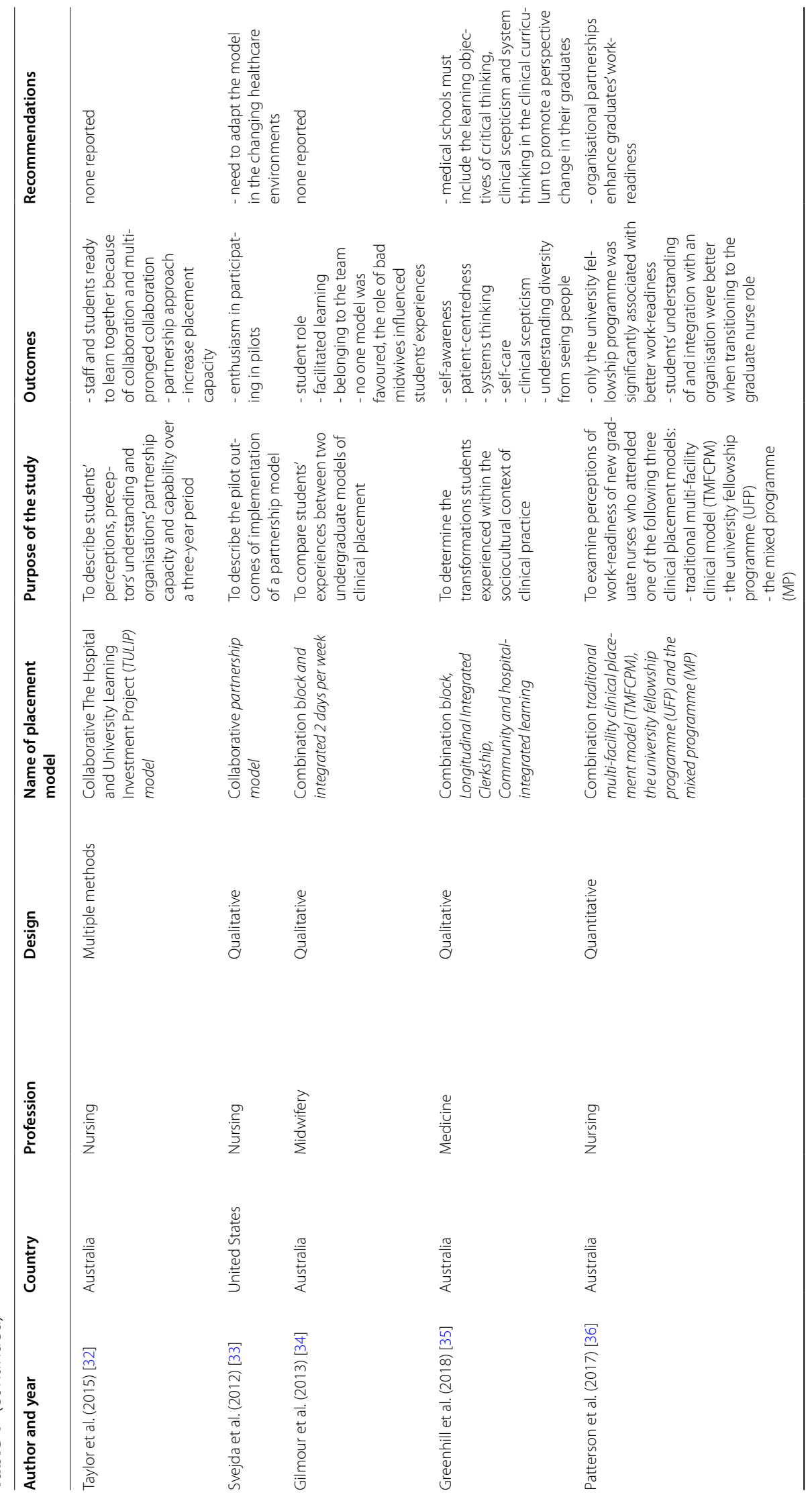




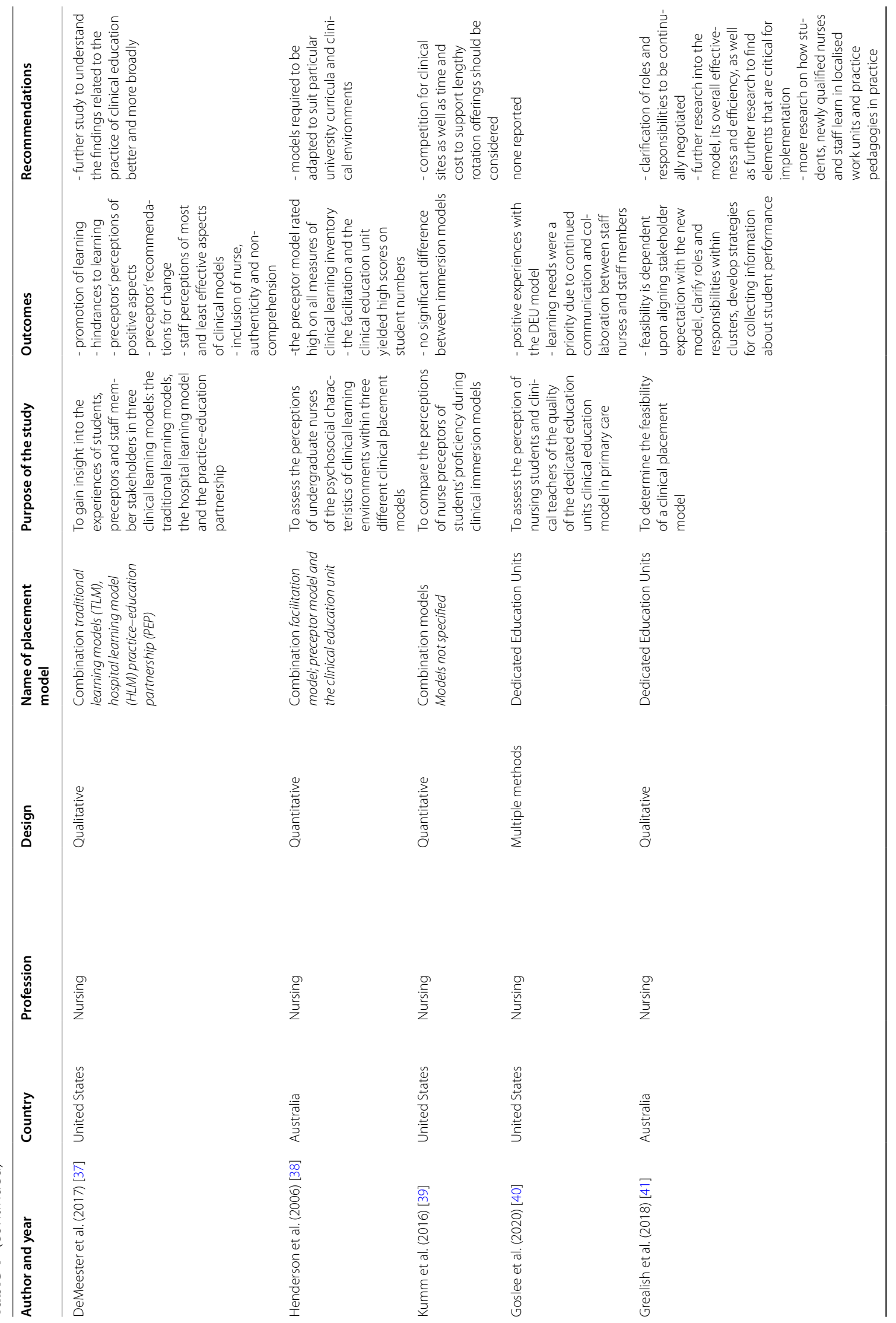




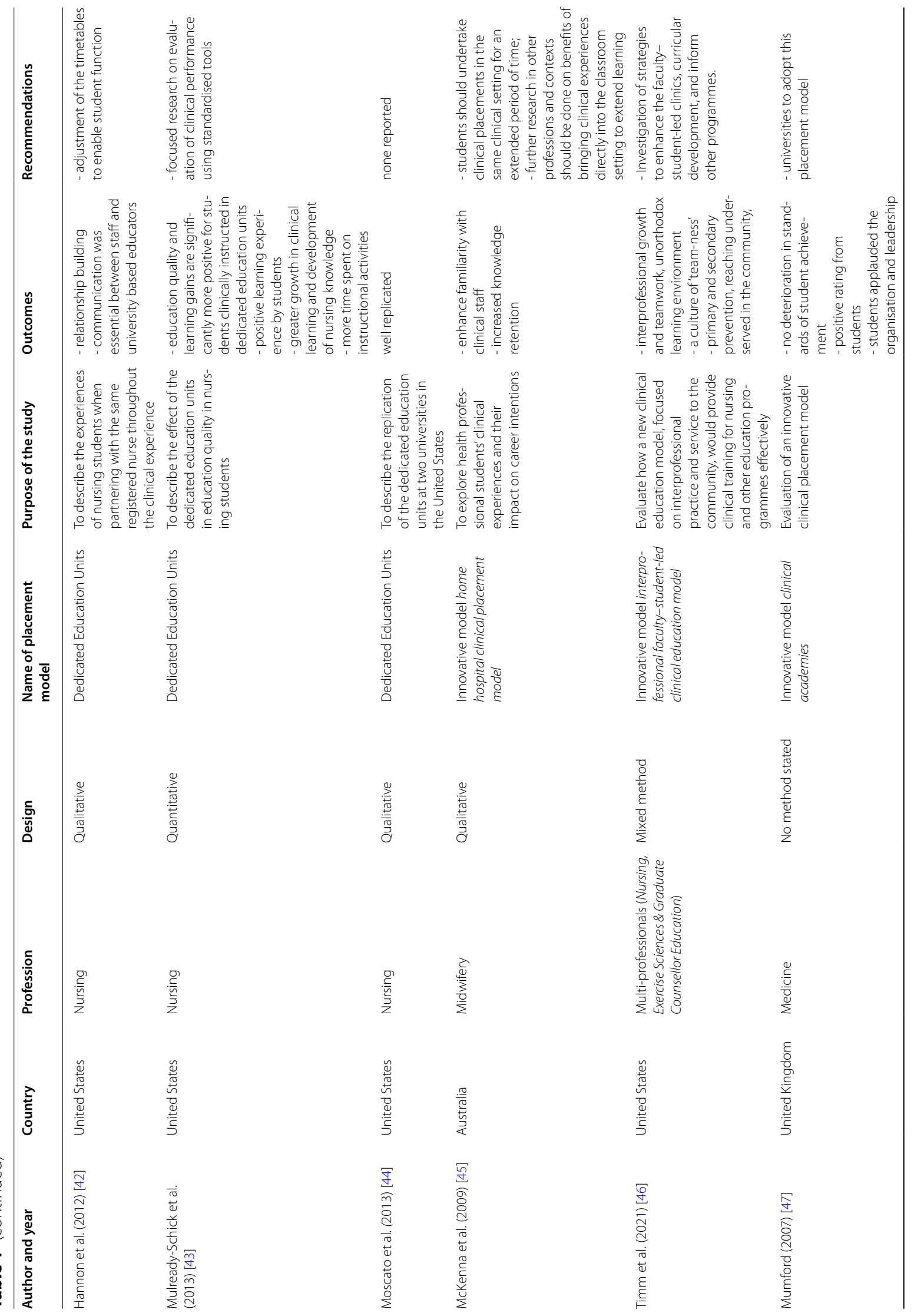




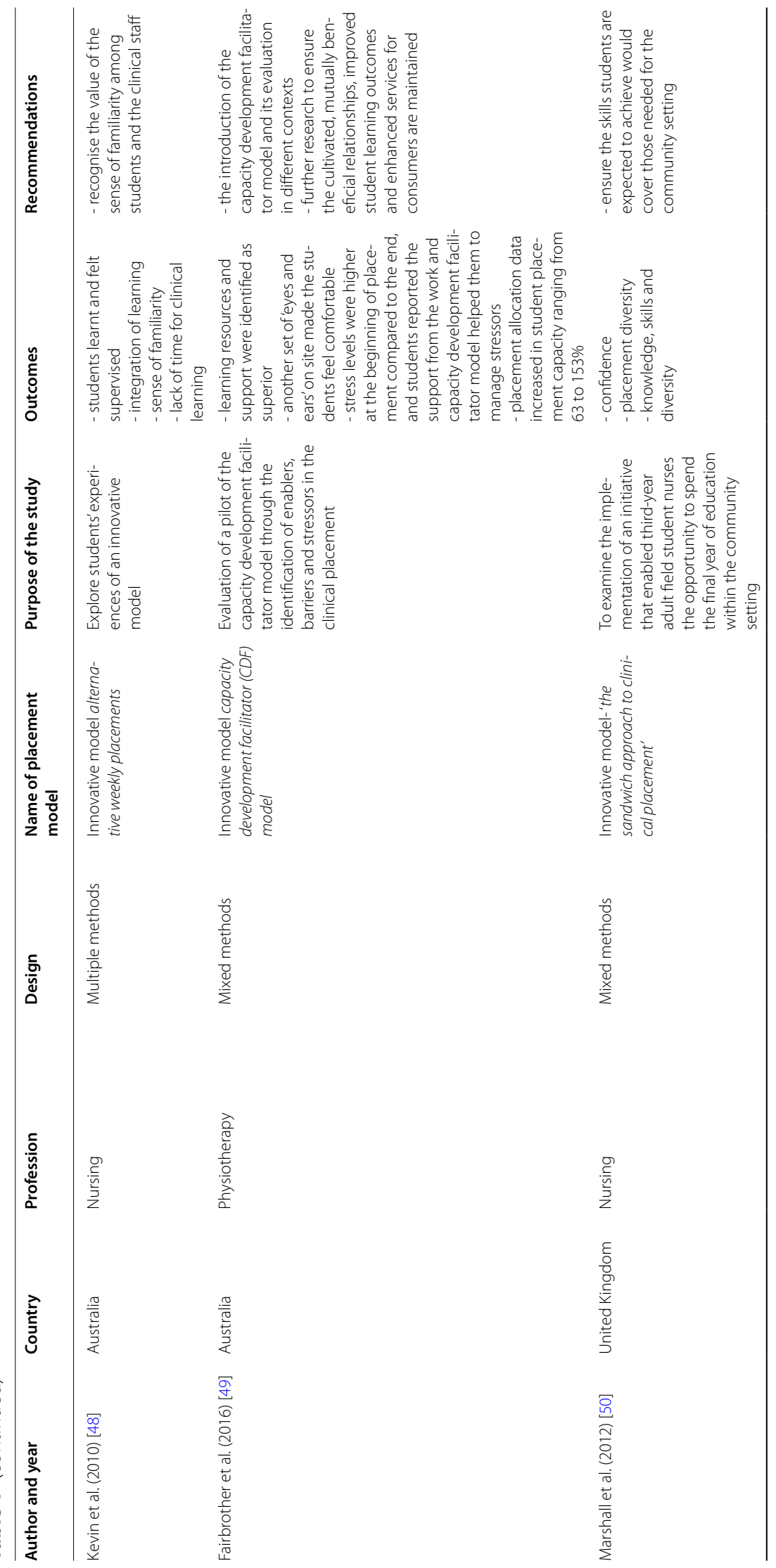




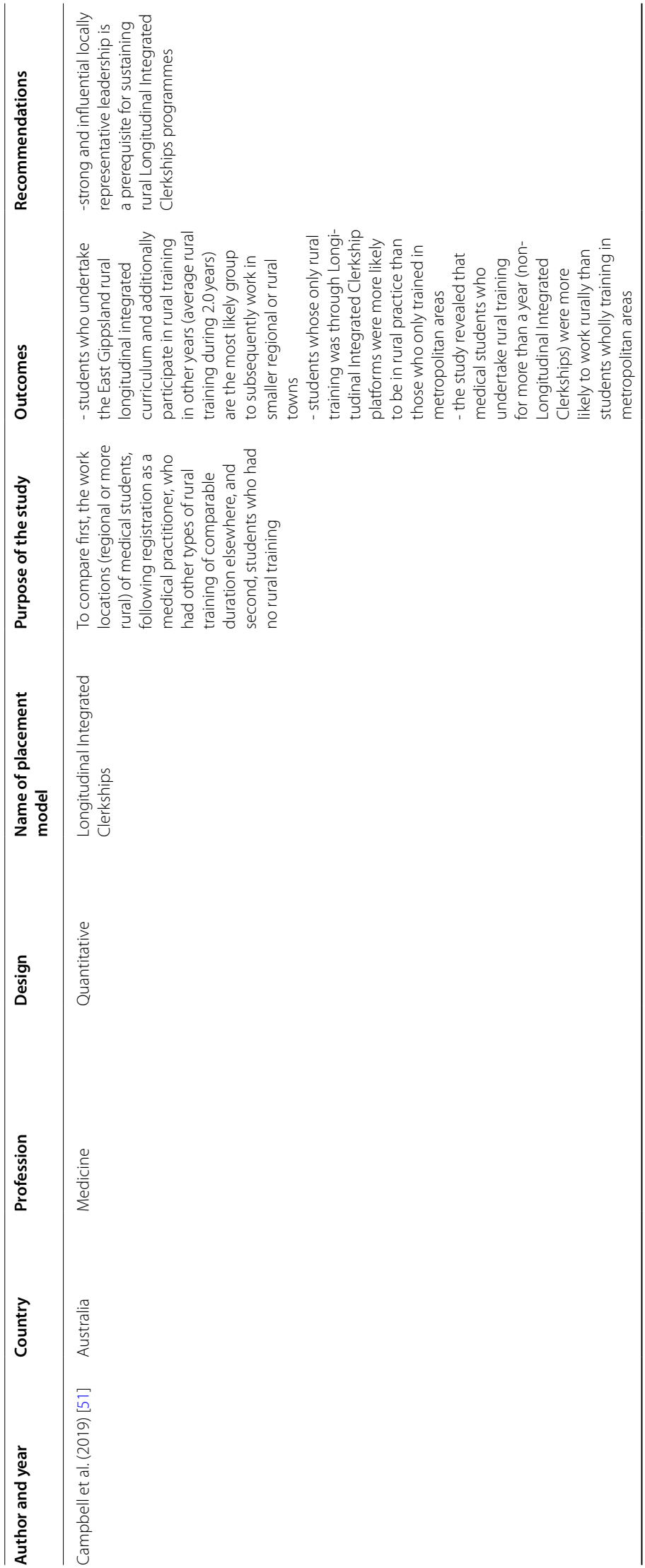




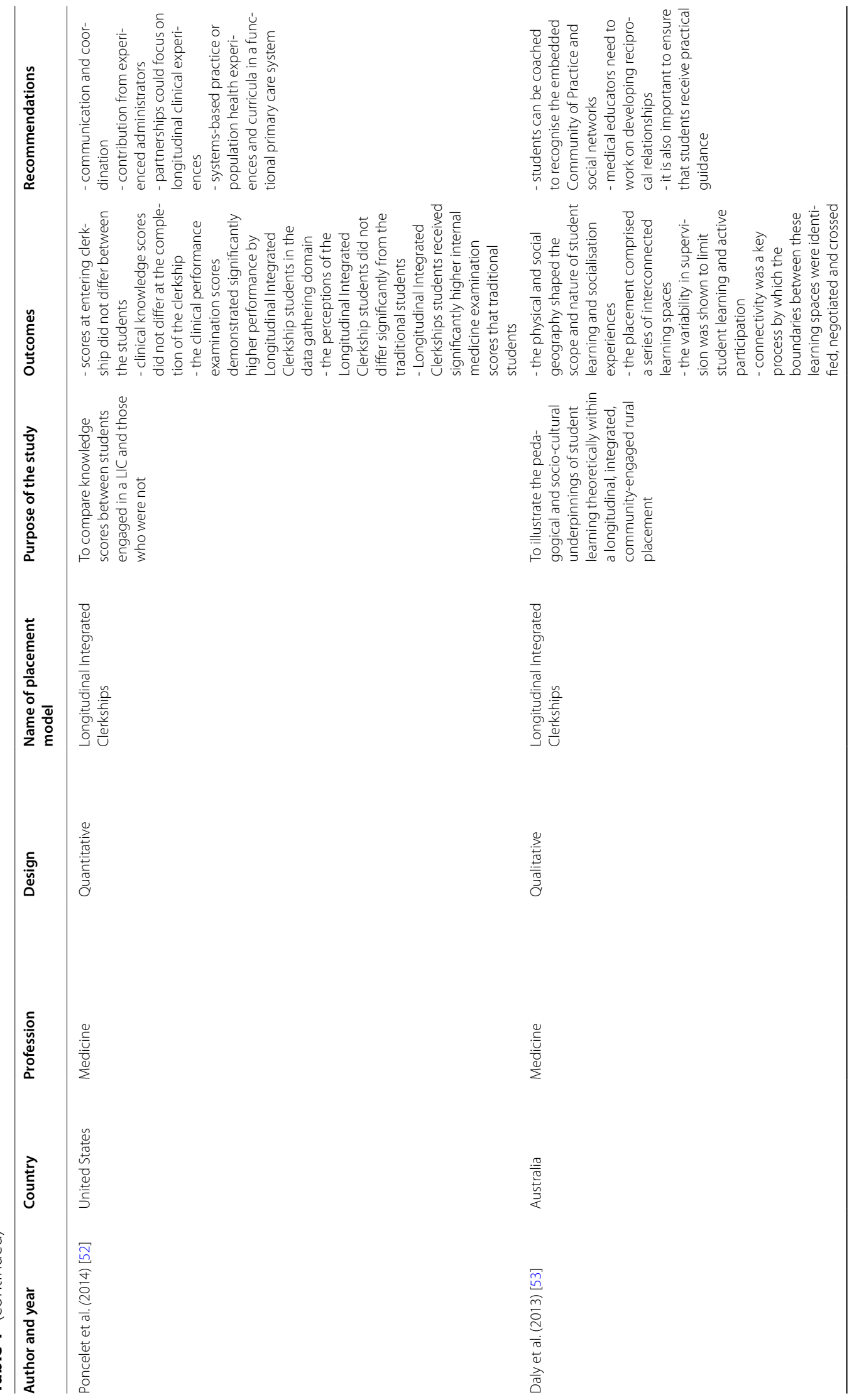




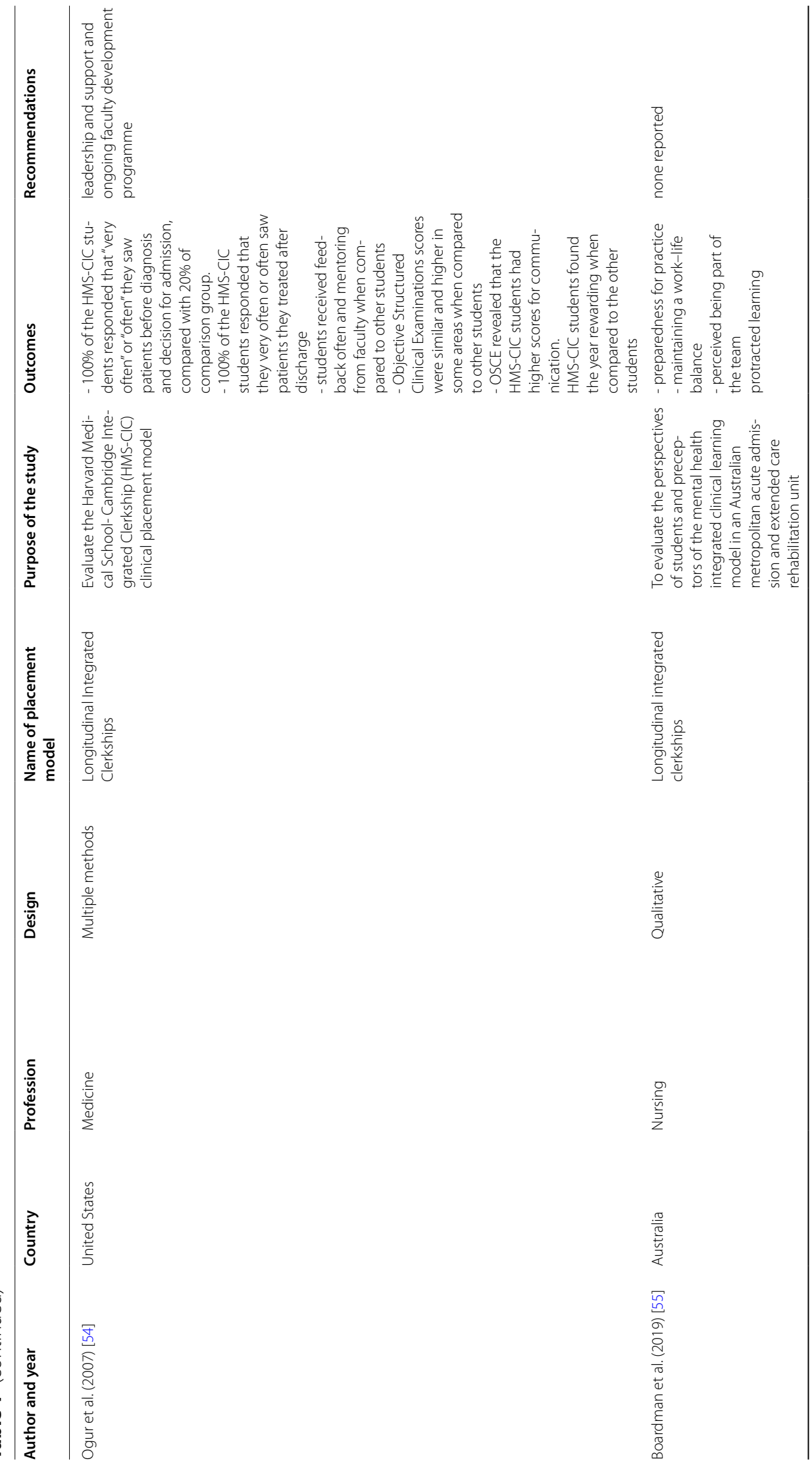




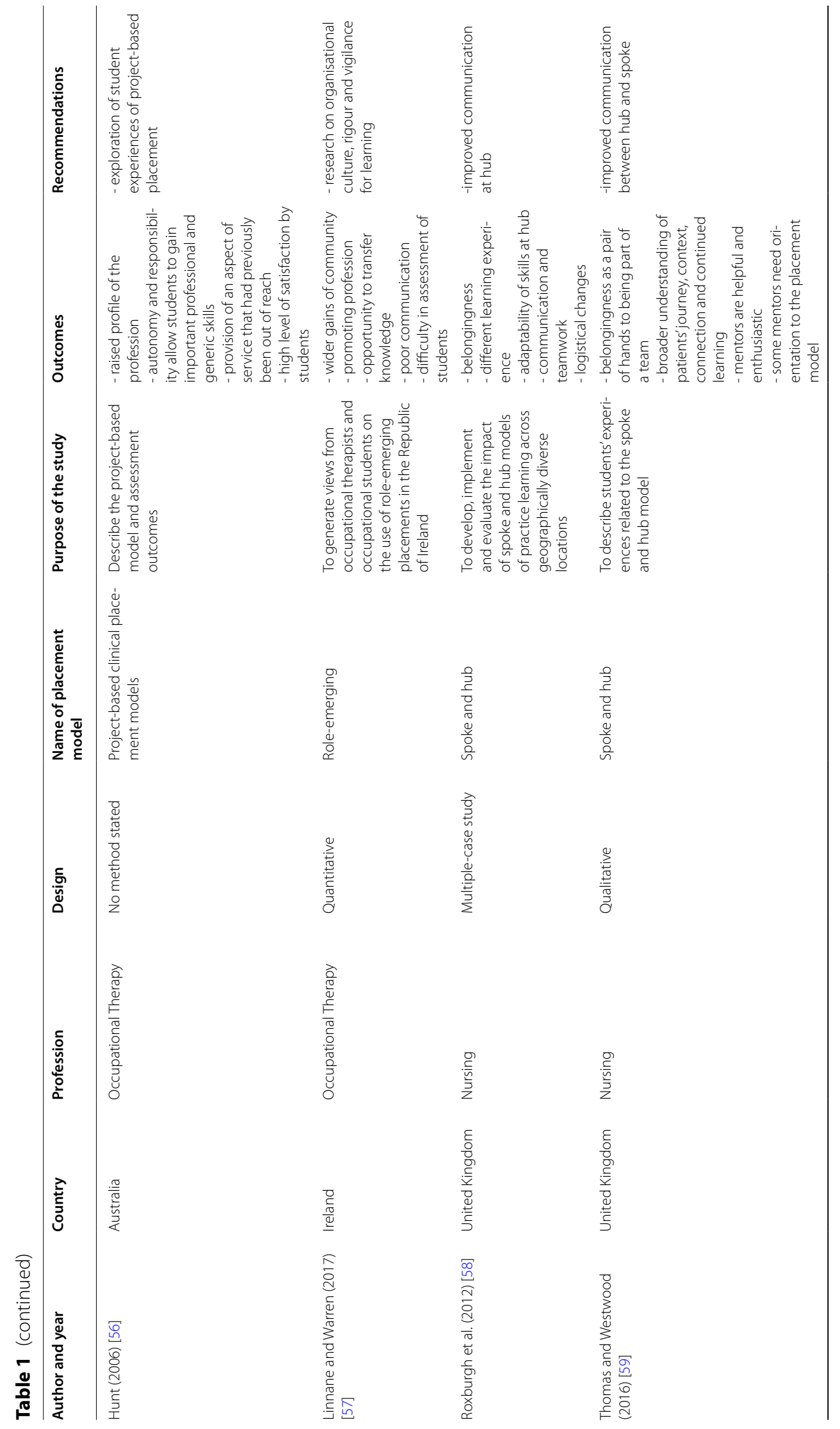




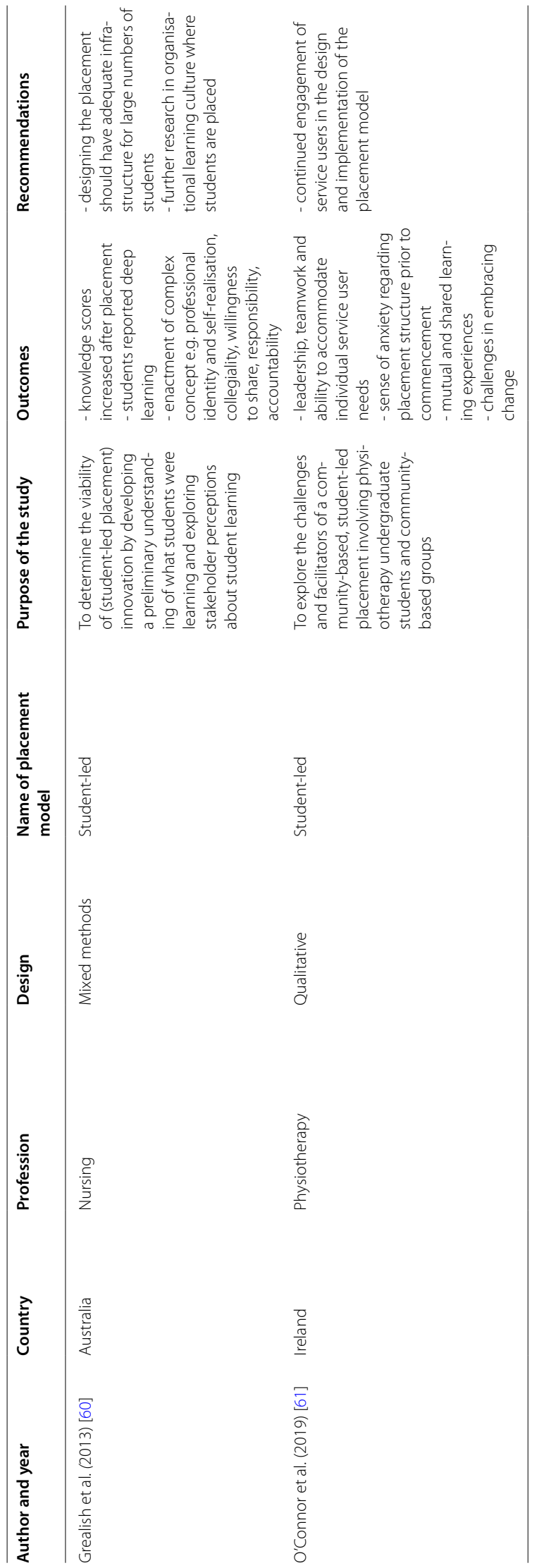


placement models used for undergraduate health professions students were reported, namely, collaborative models $(n=17 ; 7,18-33)$, combination of models $(n=6 ; 34-39)$, innovative models $(n=6 ; 45-50)$, dedicated education units $(n=5 ; 40-44)$, longitudinal integrated clerkship placement model $(n=5 ; 51-55)$, block placement model $(n=3,15-17)$, student-led placement model $(n=2 ; 60-61)$, spoke and hub placement model $(n=2 ; 58-59)$, practice- or project-based placement model $(n=1 ; 56)$ and the role-emerging placement model $(n=1 ; 57)$ (see Table 2$)$.

\section{Outcomes of the models}

Seven categories, including 19 themes, were inductively generated after engaging with the outcomes and recommendations of the included articles. The outcomes of the studies were mapped against the 19 inductively generated themes and seven categories. The majority of the themes from the review were reported among collaboration models (see Table 3).

\section{Discussion}

The purpose of this scoping review was to describe what is known on clinical placement models used in undergraduate health professions education. The majority of the included articles were from Australia and a significant number were drawn from other high-income countries, namely the United Kingdom and the United States. According to Plancikova et al. [62], these high-income countries generally have more funding for research and resources to conduct research when compared to lowincome countries predominantly in Africa and Asia. As only studies in English were included, studies from nonEnglish-speaking contexts related to clinical placement models in undergraduate health professions education were not considered. Hence, this review was skewed towards high-income English-speaking countries.

Evidence generated from undergraduate nursing dominated the number of articles included in this review, even though Medicine, Occupational Therapy, Physiotherapy, and Midwifery were also found. The literature explains that the distribution patterns of health professionals are skewed towards nursing and medicine, with nursing being the single largest group of health professionals in healthcare [4]. There are limited numbers of other health professionals including the limited number of health professions education institutions providing their training. Programme directors and administrators in Nursing and Medicine often battle with student clinical placements [61]. The large number of students enrolled in undergraduate nursing and medicine against the dwindling clinical placement opportunities in traditional clinical placement platforms may drive some programme directors to be creative in guaranteeing that their students attain professional competencies [7], the creativity can also be true with programmes will smaller student enrolments. Furthermore, professional culture, the context where the placement models is applied including issues such as finance could explain the trends of association between placement models and specific professions.

Specific professions seem to favour one clinical placement model over the other. For example, Medicine and Nursing seemed to report on clinical placement models that accommodate a large number of students, such as block placement models [34] while professions with a smaller number of students, such as occupational therapy, dominated reports on collaborative models that allow for more intimate supervision [22]. These decisions seem to be influenced by the purpose of the placement, the number of students, the placement capacity and availability of supervisors.

This review highlighted that the majority of research in the field of clinical placement models focuses on evaluating outcomes associated with the implementation of clinical placement models. The studies report on the influence of clinical placement models on the experiences of students and educators, and specific measurable outcomes, such as knowledge scores. Only two of the included articles had longitudinal outcomes inclusive of community impact. The Kirkpatrick evaluation model is a popular model for analysing and evaluating results of educational programmes [63]. According to the Kirkpatrick evaluation model, the majority of studies $(n=45)$ included in this review were aligned with the bottom two levels, namely level 1: reaction, and level 2: learning [63]. This signifies a gap in research for studies that evaluate the outcome of such clinical placement models on students, the clinical setting and the community. Longitudinal studies that evaluate the impact or higher levels of the Kirkpatrick evaluation model are therefore needed.

The outcomes of the studies included in this review were grouped into seven main categories, namely relationships, influence, the environment, facilitation, inputs, knowledge scores, and student perceptions. Firstly, relationships were reported as outcomes of specific models, such as belonging to a team [55], peer support among students [26], and helpful or positive relationships [40]. Nordquist et al, [64] explain the importance of positive relationships where students learn from and with their peers and facilitators. Students are reported as being able to learn when they are supported through positive relationships by their facilitators, their peers, and when they have a sense of belonging [59]. The establishment, development and nurturing of positive relationships among students, peers and their supervisors is an essential component of any clinical placement model and clinical 
Table 2 Brief explanation of the clinical placement models

\begin{tabular}{|c|c|}
\hline CLINICAL PLACEMENT MODEL & BRIEF EXPLANATION \\
\hline Block & $\begin{array}{l}\text { Block placement models integrate full-time clinical placements for periods of weeks within study periods or vaca- } \\
\text { tion breaks. Apprenticeship style of learning underpins block placement models. Students have to achieve specific } \\
\text { objectives which are aligned to the placement site [16]. }\end{array}$ \\
\hline Collaborative & $\begin{array}{l}\text { Collaborative placement models emphasise on the assignment of two or more students to a clinical facilitator } \\
\text { namely, 1:1; 2:1; and 3:1 placement [25]. In this review, articles that further include clinical learning dyads, preceptor } \\
\text { partnerships were included under collaborative placement models. }\end{array}$ \\
\hline Combination & $\begin{array}{l}\text { Some studies reported a combination of established clinical placement models to enhance specific outcomes. } \\
\text { Combination models in this review, reflect an amalgamation of established clinical placement models [37]. }\end{array}$ \\
\hline Dedicated Education Unit & $\begin{array}{l}\text { The dedicated education unit are models that reflect specific units or wards within a hospitals that are dedicated } \\
\text { for the clinical placement of students [41]. }\end{array}$ \\
\hline Innovative models & $\begin{array}{l}\text { Innovative models for clinical placements reflects non-conventional models for clinical placement that were } \\
\text { perceived as new by the implementers in their setting such as clinical academies, alternative weekly placements, } \\
\text { capacity development facility models and sandwich approaches [45-50] }\end{array}$ \\
\hline Longitudinal Integrated Clerkships & $\begin{array}{l}\text { Longitudinal integrated clerkships reflected a situations where students are engaged in comprehensive patient } \\
\text { care for extended periods of up to a year, through relationships with clinicians aimed at acquiring core clinical } \\
\text { competences across disciplines simultaneously [52]. }\end{array}$ \\
\hline Practice or project based & $\begin{array}{l}\text { Practice or project based models encompassed community based placement approaches where students collabo- } \\
\text { rated with the community in analysing, planning, implementing and evaluating participatory community practice } \\
\text { projects [56]. }\end{array}$ \\
\hline Role- emerging & $\begin{array}{l}\text { Role-emerging placements take place in non-conventional settings without the expected specific health profes- } \\
\text { sional employed, with supervision offered by onsite employees and also distant support from the health profes- } \\
\text { sional concerned [57]. For example placing Occupational therapy students in environments were Occupational } \\
\text { therapists do not ordinarily work, and the students being supported through distance approaches by Occupa- } \\
\text { tional therapists from their University [57]. }\end{array}$ \\
\hline Spoke and hub & $\begin{array}{l}\text { In spoke and hub models, students are allocate to a 'hub' for specific practice, and are further allocated to spoke } \\
\text { placement which is associated with the speciality of the hub with an idea of enhancing understanding of the } \\
\text { journey of the patient through healthcare setting [59]. }\end{array}$ \\
\hline Student led & Students lead service provision within their settings under the guidance of their clinical facilitators [61] \\
\hline
\end{tabular}

placement coordinators should aim towards establishing positive relationships to enhance learning.

The second outcome reported by some of the studies included in this review, was the influence of the clinical placement models on students and the communities within which they worked. The influence of the clinical placement models referred to specific benefits to the community [57], promotion of professional image [56], and even influence on the career paths of students [51]. Evidence from service-learning interventions has shown short- and long-term health influence on communities by student-led health intervention [65]. Student-driven learning cements students' understanding of the clinical environment and such understanding has been reported to influence career trajectories and promote the image of their profession [10]. However, students within the clinical setting should be supported sufficiently to promote an appropriate professional image while at the same time understanding their own professional remits to enhance their influence in the clinical environment.

The third outcome was the environment, which was reported as a complex multi-faceted structure that could enable or disable student competence development [64]. The physical environment, the patient-condition diversity, the number of students and facilitators, including the availability of resources are aspects of the clinical learning environment [66]. Fundamentally, any clinical placement model in undergraduate health professions education should cultivate a learning environment that enables students to meet their learning outcomes and develop competence. From this review, some of the included articles reflected the environment as part of the outcomes. The studies reported the implementation of specific clinical placement models to increase placement capacity [49], while others reflected on models for enhance consistency of the clinical environment and continued patient care [53]. Greenhill, et al. [35] report that their clinical placement model allowed students an opportunity to access diverse patient conditions.

Fourthly, the outcome of facilitating competence development in the clinical learning environment requires a clinical placement model that allows students to transfer learning in the clinical environment under the supervision of expert clinical educators and for opportunities of continuing feedback [23]. According to Clark [67] learning may be perceived as students integrating new concepts from their already existing knowledge schemas. The student's prior knowledge needs to be explored, before he 


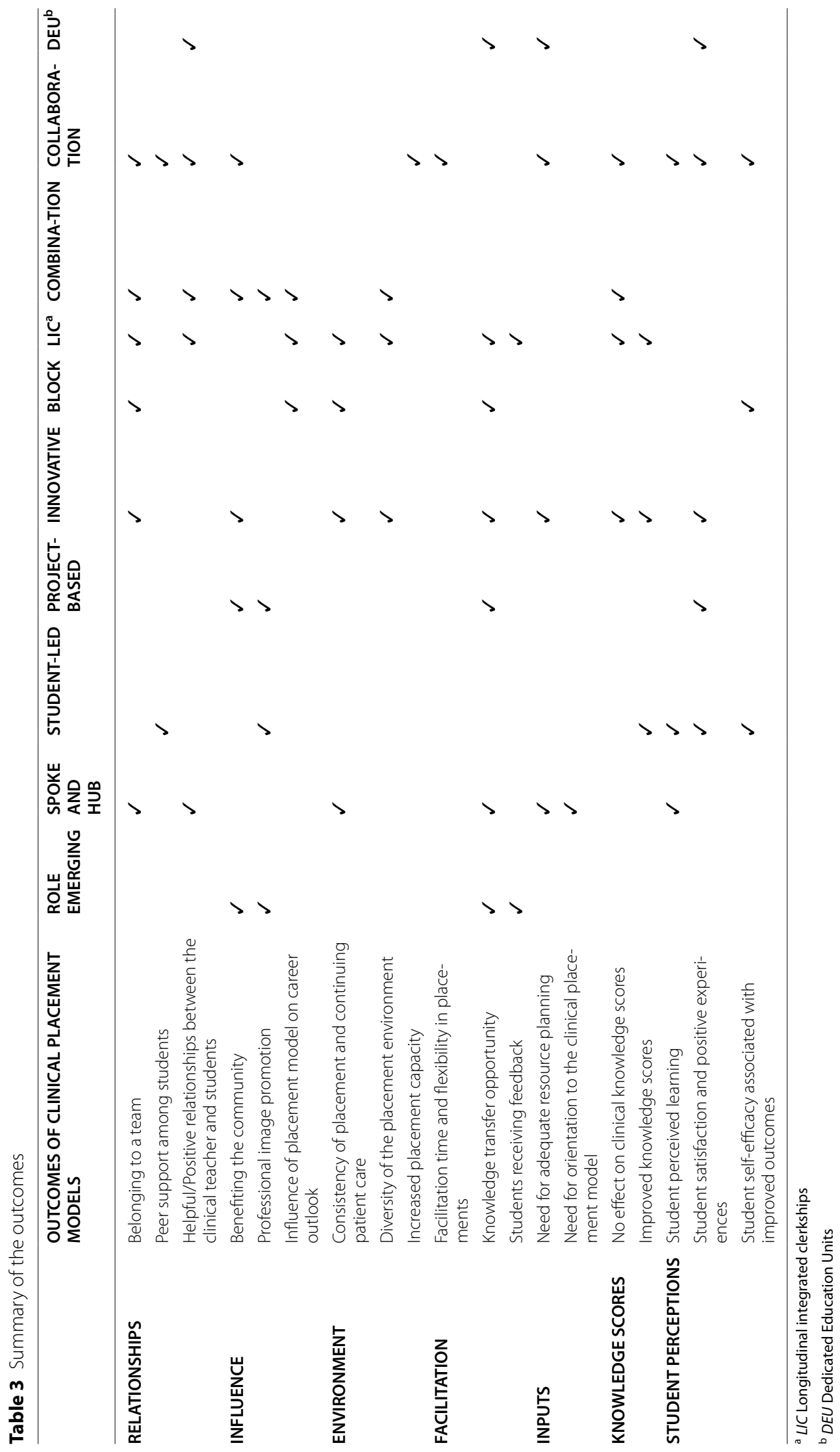


or she can assimilate and accommodate new knowledge [68]. According to this review, some clinical placement models provide an opportunity for students to transfer learning from the classroom to the clinical environment [59], while other models are flexible enough to enhance the facilitation of learning within the clinical environment. Daly et al. [53] report enhanced opportunities for student feedback as an outcome of the implementation of their clinical placement model. However, it appears as if models that had a lower supervisor and student ratio report on outcomes related to feedback opportunities, while larger numbers of students limit the opportunities for individualised feedback. Individualised feedback cements the assimilation and construction of new knowledge, especially in a complex clinical environment. However, individualised feedback opportunities may not always be possible in many health settings, especially in low- and middle-income countries that face shortages of the health workforce and educators against increased student numbers [69].

Specific inputs are necessary for the application and implementation of specific clinical placement models. In this review, some of the articles expressed a need for orientation to the clinical placement models for both the students and the clinical staff [59]. Orientation to a clinical placement model is essential for students to meet their expected clinical outcomes and for facilitators who are expected to support learning [70]. Some clinical placement models also require extraordinary resources. In their description of the dedicated education units (DEU), Springer et al. [71] state that they aimed at creating an 'ideal' clinical environment to facilitate authentic learning. However, procuring additional resources to create an ideal clinical environment may be a challenge, as additional resources may be impractical in some settings.

The implementation of some of the clinical placement models was evaluated through the examination of the sixth outcome of student knowledge scores after placement. On the one hand, some articles reported an increase in student knowledge scores attributed to the clinical placement model [54] while on the other hand, Poncelet et al. [52] reported no significant changes in student knowledge scores. Knowledge is part of competence when integrated with appropriate skills and attitudes within an authentic clinical environment [72]. Experience in the clinical environment brings to life the theoretical knowledge obtained from the classroom setting, and when valid assessments are applied, learning becomes meaningful [73]. The aim of clinical placement models should go beyond the improvement of knowledge scores towards competence attainment. A clinical placement model that contributes to competence development and attainment could contribute to a competent health workforce that influences health outcomes.

Student perception is the seventh outcome reported in the articles included in this review. Le, et al. [74] note that students are at the centre of their learning, and their perceptions and learning experiences influence the development of their self-efficacy. In the studies reviewed, some student perceived to have learnt from being included in specific clinical placement models [61], and were satisfied with their learning [56]. Nash et al. [24] report improved student self-efficacy associated with a clinical placement model. Liu [75] explains these finding through stating that students' perception of the clinical learning environment influences their learning and acceptance of important teaching and learning strategies, such as feedback. Grant [76] adds that for feedback to be meaningful and to result in learning students need to have positive perceptions of their mentors and that of learning. A negative perception and experience may increase students' cognitive load, which may become a barrier to learning [77]. Any clinical placement model used in undergraduate health professional education should foster positive perceptions and experiences, as these supports the development of self-efficacy and competence.

Studies included in this review also reported specific recommendations that should be applied in relation to each clinical placement model. In essence, the studies recommend further research on student characteristics and how such characteristics may be aligned with specific clinical placement models for optimal learning. Further research is proposed on the application of specific models in different contexts and different professions, to establish the influence of clinical placement models on learning. The included studies also recommend the investigation of organisational culture, its link to clinical placement models, and eventually learning. Practical recommendations include -

- planning for the clinical placement, such as preparation of the environment;

- guidelines for model implementation;

- sequencing of placement; and

- learning opportunities as a priority recommendation.

Specific articles emphasised the need and role for communication and coordination between the institutions, the students and the facilitators.

\section{Strengths and limitations of this review}

In establishing the rigor of this review, the authors aligned the review process and decisions on reporting with contemporary frameworks of reporting a scoping review. In addition, throughout the review process, the 
authors - who are qualified and who possess relevant experience and expertise - worked and made decisions independently but where there were discrepancies, these were resolved through discussion. A university database, accessed with the support of a university librarian generated the data for this review. The possible limitations of this review arose from the search string and inclusion criteria, which may have eliminated some studies. Such studies in non-English languages might have been beneficial and influential in terms of the outcomes of this review.

\section{Conclusion}

This study employed a scoping review methodology guided by contemporary frameworks to describe what is known from the literature regarding clinical placement models in undergraduate health professions education. The majority of these models were reported from Nursing and from Australia, with a paucity in research from low- and middle-income countries. In most of the articles reviewed, the longitudinal effect of the clinical placement models was not reported. In addition, these articles did not describe competency-development models, which align with the purpose of a clinical placement model. Various outcomes were reported as associated with specific clinical placement models, and these outcomes reflected the complexities of the clinical learning environment. Although this review was not aimed at identifying a superior clinical placement model, the outcomes of these studies demonstrate some of the essential aspects of clinical education in undergraduate health professions.

Programme directors, administrators, clinicians and educators in undergraduate health professions education are constantly faced with decisions related to the adoption of clinical placement models that enhance optimal learning influenced by calls for a radical transformation of health professions education. No single clinical placement model exists as the panacea for undergraduate health professions education; however, the context, the educational programme and educational design may be used to influence decisions on adopting a clinical placement model. Based on the insights of this scoping review of literature on clinical placement models we recommend the following essential elements that may be integrated to enhance learning among undergraduate health professions students:

- all models need to prioritise the establishment, development and nurturing of positive relationships between students, peers, and their facilitators;

- students in clinical placements must be supported by experienced professionals;
- students need to be facilitated to meet competence through individualised feedback;

- all clinical placement models need specific orientation and resources; and

- clinical placement models should incorporate the development of positive learning experiences and perceptions from students.

Further longitudinal research could focus on the effect of specific models on students, the clinical environment and community outcomes. As clinical learning is fundamental to undergraduate health professions education, students need to be exposed to clinical environments that enable the development of their competence. Insight into outcomes reported in the literature could guide educators in their quest to transform undergraduate health professions education. In doing this, programme directors, administrators, clinicians and educators could provide innovative programmes that would foster optimal learning for the development of competent health professions graduates who may positively influence health outcomes in many communities.

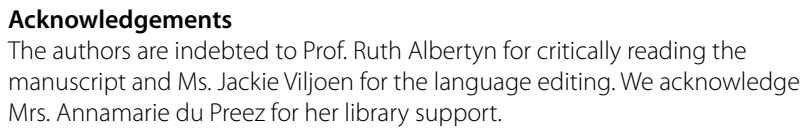

\section{Authors' contributions}

C.N.N.., L.H.VD.,Y.B., conceptualised the study, and analysed the data. C.N.N. wrote the initial article draft and L.H.VD and Y.B. reviewed the draft. All authors reviewed and finalised the manuscript. The author(s) read and approved the final manuscript.

\section{Funding}

Not applicable.

Availability of data and materials

All data sets used and/or analysed during the current review are available from the corresponding author on reasonable request.

\section{Declarations}

Ethics approval and consent to participate

The Health Sciences Research Ethics Committee (HSREC) of the University of the Free State approved this scoping review (HSD 2020/0572/2605).

\section{Consent for publication}

Not applicable.

\section{Competing interests}

The authors declare that they have no competing interests.

Received: 25 February 2021 Accepted: 8 November 2021 Published online: 04 December 2021

\section{References}

1. Frenk J, Chen L, Bhutta ZA, et al. Health professionals for a new century: transforming education to strengthen health systems in an interdependent world. Lancet. 2010;376(9756):1923-58. https://doi.org/10.1016/ S0140-6736(10)61854-5. 
2. World Health Organization (WHO). Framework for action on interprofessional education \& collaborative practice. Geneva: WHO Press; 2010. http://www.who.int/hrh/nursing_midwifery/en/. Accessed 15 May 2019.

3. Irby DM, Cooke M, Brien BCO. Calls for reform of medical education by the Carnegie Foundation for the Advancement of Teaching: 1910 and 2010. Acad Med. 2010;85(2):220-7.

4. World Health Organization. State of the World Nursing Report 2020: investing in education, jobs and leadership. Geneva: WHO Press; 2020.

5. Keeping-Burke L, McCloskey R, Donovan C, Yetman L, Hansen L. Nursing students' experiences with clinical placement in residential aged care facilities. JBI Database System Rev Implement Rep. 2018;16(5):1 109-16. https://doi.org/10.11124/JBISRIR-2017-003495.

6. Lekkas P, Larsen T, Kumar S, et al. No model of clinical education for physiotherapy students is superior to another: a systematic review. Aust J Physiother. 2007;53(1):19-28. https://doi.org/10.1016/50004-9514(07) 70058-2.

7. Cohen SR, Thomas CR, Gerard C. The clinical learning dyad model: an innovation in midwifery education. J Midwifery Womens Health. 2015;60(6):691-8. https://doi.org/10.1111/jmwh.12363.

8. Kerdijk W, Snoek JW, Van Hell EA, Cohen-Schotanus J. The effect of implementing undergraduate competency-based medical education on students' knowledge acquisition, clinical performance and perceived preparedness for practice: a comparative study. BMC Med Educ. 2013;13:76-84. https://doi.org/10.1186/1472-6920-13-76.

9. Mackintosh-Franklin C. Pedagogical principles underpinning undergraduate nurse education in the UK: a review. Nurse Educ Today. 2016:40:11822. https://doi.org/10.1016/j.nedt.2016.02.015.

10. Amineh RJ, Asl HD. Review of constructivism and social constructivism. J Soc Sci Lit Lang. 2015;1:9-16.

11. Aromataris E, Munn Z. In: Aromataris E, Munn Z, editors. JBI manual for evidence synthesis. Sydney: JBl; 2020. https://doi.org/10.46658/ JBIMES-20-01.

12. Munn Z, Peters MDJ, Stern C, Tufanaru C, McArthur A, Aromataris E. Systematic review or scoping review? Guidance for authors when choosing between a systematic or scoping review approach. BMC Med Res Methodol. 2018;18(1):143. https://doi.org/10.1186/s12874-018-0611-x.

13. Tricco AC, Lillie E, Zarin W, et al. PRISMA extension for scoping reviews (PRISMA-SCR): checklist and explanation. Ann Intern Med. 2018;169(7):467. https://doi.org/10.7326/M18-0850.

14. Moher D, Shamseer $L$, Clarke M, et al. Preferred reporting items for systematic review and meta-analysis protocols (PRISMA-P) 2015 statement. Syst Rev. 2015;4(1):1. https://doi.org/10.1186/2046-4053-4-1.

15. McDonnel Smedts A, Lowe MP. Efficiency of clinical training at the Northern Territory clinical school: placement length and rate of return for internship. Med J Aust. 2008;189(3):166-8. https://doi.org/10.5694/j.13265377.2008.tb01953.x.

16. Birks M, Bagley T, Park T, Burkot C, Mills J. The impact of clinical placement model on learning in nursing: a descriptive exploratory study. Aust J Adv Nurs. 2017;34(3):16-23.

17. Kell C, Owen G. Approaches to learning on placement: the students' perspective. Physiother Res Int. 2009;14(2):105-15. https://doi.org/10.1002/ pri.422.

18. Blakely C, Rigg J, Joynson K, Oldfield S. Supervision models in a 2:1 acute care placement. Br J Occup Ther. 2009;72(11):515-7. https://doi.org/10. 4276/030802209X12577619071181.

19. Kreulen GJ, Bednarz PK, Wehrwein T, Davis J. Clinical education partnership: a model for school district and college of nursing collaboration. J Sch Nurs. 2008;24(6):360-9. https://doi.org/10.1177/1059840508325429.

20. Newton JM, Jolly BC, Ockerby CM, Cross WM. Student centredness in clinical learning: the influence of the clinical teacher. J Adv Nurs. 2012;68(10):2331-40. https://doi.org/10.1111/j.1365-2648.2012.05946.x.

21. Newton JM, Cross WM, White K, Ockerby C, Billett S. Outcomes of a clinical partnership model for undergraduate nursing students. Contemp Nurse. 2011;39(1):119-27. https://doi.org/10.5172/conu.2011.39.1.119

22. Bhagwat $M$, Hewetson $R$, Jones $L$, et al. Comparison of paired and single clinical placement models: a time-use analysis. Int I Lang Commun Disord. 2018;53(3):468-79. https://doi.org/10.1111/1460-6984.12360.

23. Lynam A-M, Corish C, Connolly D. Development of a framework to facilitate a collaborative peer learning 2:1 model of practice placement education. Nutr Diet. 2015;72(2):170-5. https://doi.org/10.1111/17470080.12133.
24. Nash R, Lemcke P, Sacre S. Enhancing transition: an enhanced model of clinical placement for final year nursing students. Nurse Educ Today. 2009;29(1):48-56. https://doi.org/10.1016/j.nedt.2008.06.004.

25. Martin M, Morris J, Moore A, Sadlo G, Crouch V. Evaluating practice education models in occupational therapy: comparing 1:1, 2:1 and 3:1 placements. Br J Occup Ther. 2004;67(5):192-200. https://doi.org/10. 1177/030802260406700502.

26. Alpine LM, Caldas FT, Barrett EM. Evaluation of a 2 to 1 peer placement supervision model by physiotherapy students and their educators. Physiother Theory Pract. 2019;35(8):748-55. https://doi.org/10.1080/09593985. 2018.1458168.

27. Moore A, Morris J, Crouch V, Martin M. Evaluation of physiotherapy clinical educational models. Physiotherapy. 2003;89(8):489-501. https://doi. org/10.1016/50031-9406(05)60007-7.

28. Price $D$, Whiteside M. Implementing the 2:1 student placement model in occupational therapy: strategies for practice. Aust Occup Ther J. 2016;63(2):123-9. https://doi.org/10.1111/1440-1630.12257.

29. O'Connor A, Cahill M, McKay EA. Revisiting 1:1 and 2:1 clinical placement models: student and clinical educator perspectives. Aust Occup Ther J. 2012;59(4):276-83. https://doi.org/10.1111/j.1440-1630.2012.01025.x.

30. Barnett T, Cross M, Shahwan-Akl L, Jacob E. The evaluation of a successful collaborative education model to expand student clinical placements. Nurse Educ Pract. 2010;10(1):17-21. https://doi.org/10.1016/j.nepr.2009. 01.018.

31. Didion J, Kozy MA, Koffel C, Oneail K. Academic/clinical partnership and collaboration in quality and safety education for nurses' education. J Prof Nurs. 2013;29(2):88-94. https://doi.org/10.1016/j.profnurs.2012.12.004.

32. Taylor MA, Brammer JD, Cameron M, Perrin CA. The sum of all parts: an Australian experience in improving clinical partnerships. Nurse Educ Today. 2015;35(2):297-303. https://doi.org/10.1016/j.nedt.2014.10.003.

33. Svejda M, Goldberg J, Belden M, Potempa K, Calarco M. Building the clinical bridge to advance education, research, and practice excellence. Nurs Res Pract. 2012;2012(1):1-10. https://doi.org/10.1155/2012/826061.

34. Gilmour C, Mclntyre M, McLelland G, Hall H, Miles M. Exploring the impact of clinical placement models on undergraduate midwifery students. Women Birth. 2013;26(1):e21-5. https://doi.org/10.1016/j.wombi. 2012.06.004.

35. Greenhill J, Richards JN, Mahoney S, Campbell N, Walters L. Transformative learning in medical education. J Transform Educ. 2018;16(1):58-75. https://doi.org/10.1177/1541344617715710.

36. Patterson EEB, Boyd L, Mnatzaganian G. The impact of undergraduate clinical teaching models on the perceptions of work-readiness among new graduate nurses: a cross sectional study. Nurse Educ Today. 2017;55:101-6. https://doi.org/10.1016/j.nedt.2017.05.010.

37. DeMeester DA, Hendricks S, Stephenson E, Welch JL. Student, preceptor, and faculty perceptions of three clinical learning models. J Nurs Educ. 2017;56(5):281-6. https://doi.org/10.3928/01484834-20170421-05.

38. Henderson A, Twentyman M, Heel A, Lloyd B. Students' perception of the psycho-social clinical learning environment: an evaluation of placement models. Nurse Educ Today. 2006;26(7):564-71. https://doi.org/10.1016/j. nedt.2006.01.012.

39. Kumm S, Godfrey N, Richards V, Hulen J, Ray K. Senior student nurse proficiency: a comparative study of two clinical immersion models. Nurse Educ Today. 2016;44:146-50. https://doi.org/10.1016/j.nedt.2016.05.023.

40. Goslee E, Chesak S, Forsyth DM, Foote J, Bergen S. Implementation of a dedicated education unit model for ADN students in a rural primary care setting. Nurse Educ. 2020;45(2):97-101. https://doi.org/10.1097/NNE. 0000000000000711.

41. Grealish L, Van de Mortel T, Brown C, et al. Redesigning clinical education for nursing students and newly qualified nurses: a quality improvement study. Nurse Educ Pract. 2018;33:84-9. https://doi.org/10.1016/j.nepr. 2018.09.005.

42. Hannon P, Hunt C, Haleem D, King L, Day L, Casals P. Implementation of a dedicated education unit for baccalaureate students: process and evaluation. Int J Nurs Educ. 2012;4(2):155-9.

43. Mulready-Shick J, Flanagan KM, Banister GE, Mylott L, Curtin LJ. Evaluating dedicated education units for clinical education quality. J Nurs Educ. 2013;52(11):606-14. https://doi.org/10.3928/01484834-20131014-07.

44. Moscato SR, Nishioka VM, Coe MT. Dedicated education unit: implementing an innovation in replication sites. J Nurs Educ. 2013;52(5):259-67. https://doi.org/10.3928/01484834-20130328-01. 
45. McKenna LG, Wray N, McCall L. Exploring continuous clinical placement for undergraduate students. Adv Health Sci Educ. 2009;14(3):327-35. https://doi.org/10.1007/s10459-008-9116-4.

46. Timm JR, Schnepper LL. A mixed-methods evaluation of an interprofessional clinical education model serving students, faculty, and the community. J Interprof Care. 2021;35(1):92-100. https://doi.org/10.1080/ 13561820.2019.1710117.

47. Mumford DB. Clinical Academies: innovative school-health service partnerships to deliver clinical education. Acad Med. 2007;82(5):435-40

48. Kevin J, Callaghan A, Driver C, Ellis J, Jacobs B. A possible alternative model of clinical experience for student nurses. J Nurses Staff Dev. 2010;26(5):E5-9. https://doi.org/10.1097/NND.0b013e3181b1ba07.

49. Fairbrother M, Nicole M, Blackford J, Nagarajan SV, Mcallister L. A new model of clinical education to increase student placement availability: the capacity development facilitator model. Asia-Pacific J Coop Educ. 2016;17(1):45-59.

50. Marshall P, Shelton R. Preparing nursing students to be community health practitioners. Br J Community Nurs. 2012;17(12):622-9. https://doi.org/10. 12968/bjcn.2012.17.12.622.

51. Campbell D, McGrail M, O'Sullivan B, Russell D. Outcomes of a 1-year longitudinal integrated medical clerkship in small rural Victorian communities. Rural Remote Health. 2019;19:4987. https://doi.org/10.22605/RRH49 87.

52. Poncelet A, Mazotti L, Blumberg B, Wamsley MA, Grennan T, Shore WB. Creating a longitudinal integrated clerkship with mutual benefits for an academic medical center and a community health system. Perm J. 2014;18(2):50-6. https://doi.org/10.7812/TPP/13-137.

53. Daly M, Roberts C, Kumar K, Perkins D. Longitudinal integrated rural placements: a social learning systems perspective. Med Educ. 2013;47(4):352-61. https://doi.org/10.1111/medu.12097.

54. Ogur B, Hirsh D, Krupat E, Bor D. The Harvard Medical School-Cambridge integrated clerkship: an innovative model of clinical education. Acad Med. 2007:82(4):397-404. https://doi.org/10.1097/ACM.0b013e3180 $3338 f 0$.

55. Boardman G, Lawrence K, Polacsek M. Undergraduate student nurses' perspectives of an integrated clinical learning model in the mental health environment. Int J Ment Health Nurs. 2019;28(1):96-104. https://doi.org/ 10.1111/inm.12496

56. Hunt SG. A practice placement education model based upon a primary health care perspective used in South Australia. Br J Occup Ther. 2006;69(2):81-5. https://doi.org/10.1177/030802260606900206.

57. Linnane $E$, Warren A. Therapist and student views of the role emerging placement model in the Republic of Ireland. Irish J Occup Ther. 2017:45(1):40-51. https://doi.org/10.1108/IJOT-01-2017-0002.

58. Roxburgh M, Conlon M, Banks D. Evaluating hub and spoke models of practice learning in Scotland, UK: a multiple case study approach. Nurse Educ Today. 2012;32(7):782-9. https://doi.org/10.1016/j.nedt.2012.05.004.

59. Thomas M, Westwood N. Student experience of hub and spoke model of placement allocation: an evaluative study. Nurse Educ Today. 2016;46:248. https://doi.org/10.1016/j.nedt.2016.08.019.

60. Grealish L, Lucas N, Neill J, McQuellin C, Bacon R, Trede F. Promoting student learning and increasing organizational capacity to host students in residential aged care: a mixed method research study. Nurse Educ Today. 2013;33(7):714-9. https://doi.org/10.1016/j.nedt.2012.11.017.

61. O'Connor A, Liston $E$, O'Donnell M. Student-led community placement in physiotherapy. Clin Teach. 2019;16(6):593-7. https://doi.org/10.1111/tct. 12988.

62. Plancikova D, Duric P, O'May F. High-income countries remain overrepresented in highly ranked public health journals: a descriptive analysis of research settings and authorship affiliations. Crit Public Health. 2020:1-7. https://doi.org/10.1080/09581596.2020.1722313.

63. Frantz JM, Bezuidenhout J, Burch VC, et al. The impact of a faculty development programme for health professions educators in sub-Saharan Africa: an archival study. BMC Med Educ. 2015;15(1):28. https://doi.org/10 1186/s12909-015-0320-7.

64. Nordquist J, Hall J, Caverzagie K, et al. The clinical learning environment. Med Teach. 2019;41(4):366-72. https://doi.org/10.1080/0142159X.2019. 1566601.

65. Vroman K, Simmons CD, Knight J. Service learning can make occupationbased practice a reality: a single case study. Occup Ther Heal Care 2010;24(3):249-65. https://doi.org/10.3109/07380571003706058.
66. Arkan B, Ordin Y, YIImaz D. Undergraduate nursing students' experience related to their clinical learning environment and factors affecting to their clinical learning process. Nurse Educ Pract. 2018;29:127-32. https:// doi.org/10.1016/j.nepr.2017.12.005.

67. Clark KR. Learning theories: Constructivism. Radiol Technol. 2018;90:180-2.

68. Taylor DCM, Hamdy H. Adult learning theories: implications for learning and teaching in medical education: AMEE guide no. 83. Med Teach. 2013;35(11):e1561-72. https://doi.org/10.3109/0142159X.2013.828153.

69. Downes E, Blount S, Belatchew M, Mustafa A, Wold J. Strengthening educational capacity through context-relevant curriculum design and evaluation. Front Educ. 2017;2(July):1-5. https://doi.org/10.3389/feduc. 2017.00029.

70. Shupp P. Rethinking new student orientation. Owner of site; 2014. http:// wsac.wa.gov/sites/default/files/2014/ptw\%2836\%29.pdf Accessed day month year.

71. Springer PJ, Johnson P, Lind B, Walker E, Clavelle J, Jensen N. The Idaho dedicated education unit model. Nurse Educ. 2012;37(6):262-7. https:// doi.org/10.1097/NNE.0b013e31826f2c4e.

72. Fernandez N, Dory V, Ste-Marie L-G, Chaput M, Charlin B, Boucher A. Varying conceptions of competence: an analysis of how health sciences educators define competence. Med Educ. 2012;46(4):357-65. https://doi. org/10.1111/j.1365-2923.2011.04183.x.

73. Brashers V, Haizlip J, Owen JA. The ASPIRE model: grounding the IPEC core competencies for interprofessional collaborative practice within a foundational framework. J Interprof Care. 2019;34(1):1-5. https://doi.org/ 10.1080/13561820.2019.1624513.

74. Le C, Wolfe RE, Steinberg A. The past and the promise: today's competency education movement. Students at the Center: Competency Education Research Series. Jobs for the Future. Publisher; 2014. https:// eric.ed.gov/?id=ED561253 Accessed 15 Jan, 2021.

75. Liu C, Wang $\mathrm{H}$, Zhou $\mathrm{L}$, et al. Sources and symptoms of stress among nurses in the first Chinese anti-Ebola medical team during the Sierra Leone aid mission: a qualitative study. Int J Nurs Sci. 2019;6(2):187-91.

76. Grant J. Principles of curriculum design. In: Understanding medical education: evidence, theory and practice. 2nd ed. Place: Publisher; 2013. p. 31-46. https://doi.org/10.1002/9781118472361.ch3.

77. Kirschner PA. Cognitive load theory: implications of cognitive load theory on the design of learning. Learn Instr. 2002;12(1):1-10. https://doi.org/10. 1016/S0959-4752(01)00014-7.

\section{Publisher's Note}

Springer Nature remains neutral with regard to jurisdictional claims in published maps and institutional affiliations.

Ready to submit your research? Choose BMC and benefit from:

- fast, convenient online submission

- thorough peer review by experienced researchers in your field

- rapid publication on acceptance

- support for research data, including large and complex data types

- gold Open Access which fosters wider collaboration and increased citations

- maximum visibility for your research: over $100 \mathrm{M}$ website views per year

At BMC, research is always in progress.

Learn more biomedcentral.com/submissions 